\title{
Estuarine Gradients Dictate Spatiotemporal Variations of Microbiome Networks in the Chesapeake Bay
}

\author{
Hualong Wang \\ Ocean University of China \\ Feng Chen \\ University of Maryland Center for Environmental Science \\ Chuanlun Zhang \\ Southern University of Science and Technology \\ Min Wang \\ Ocean University of China \\ Jinjun Kan ( $\sigma_{\text {jkan@stroudcenter.org ) }}$ \\ Stroud Water Research Center https://orcid.org/0000-0001-5331-380X
}

\section{Research article}

Keywords: Estuarine gradients, planktonic microbiomes, co-occurrence, network stability, Chesapeake Bay

Posted Date: October 26th, 2021

DOI: https://doi.org/10.21203/rs.3.rs-1001476/v1

License: (c) (i) This work is licensed under a Creative Commons Attribution 4.0 International License. Read Full License

Version of Record: A version of this preprint was published at Environmental Microbiome on November 27th, 2021. See the published version at https://doi.org/10.1186/s40793-021-00392-z. 


\section{Abstract}

Background: Annually reoccurring microbial populations with strong spatial and temporal variations have been identified in estuarine environments, especially in those with long residence time such as the Chesapeake Bay (CB). However, it is unclear how microbial taxa cooccurrence with each other and how the intertaxa networks respond to the strong environmental gradients in the estuaries.

Results: Here, we constructed co-occurrence networks on prokaryotic microbial communities in the CB, which included seasonal samples from seven spatial stations along the salinity gradients for three consecutive years. Our results showed that spatiotemporal variations of planktonic microbiomes promoted differentiations of the characteristics and stability of prokaryotic microbial networks in the CB estuary. Prokaryotic microbial networks exhibited a clear seasonal pattern where microbes were more closely connected during warm season compared to the associations during cold season. In addition, microbial networks were more stable in the lower Bay (ocean side) than those in the upper Bay (freshwater side). Multivariate regression tree (MRT) analysis and piecewise structural equation modeling (SEM) indicated that temperature, salinity and total suspended substances along with nutrient availability, particulate carbon and Chl a, affected the distribution and co-occurrence of microbial groups, such as Actinobacteria, Bacteroidetes, Cyanobacteria, Planctomycetes, Proteobacteria, and Verrucomicrobia. Interestingly, compared to the abundant groups (such as SAR11, Saprospiraceae and Actinomarinaceae), the rare taxa including OM60(NOR5) clade (Gammaproteobacteria), Micrococcales (Actinobacteria), and NS11-12 marine group (Bacteroidetes) contributed greatly to the stability of microbial co-occurrence in the Bay. Modularity and cluster structures of microbial networks varied spatiotemporally, which provided valuable insights into the 'small world' (a group of more interconnected species), network stability, and habitat partitioning/preferences.

Conclusion: Our results shed light on how estuarine gradients alter the spatiotemporal variations of prokaryotic microbial networks in the estuarine ecosystem, as well as their adaptability to environmental disturbances and co-occurrence network complexity and stability.

\section{Background}

Planktonic microbiomes comprise both free-living organisms and those attached to particles, which is typical and visible in water columns of estuaries. The planktonic microbiomes in estuaries are one of the most active microbial communities [1] and they contribute primarily to the most productive environments on the planet [2]. For example, estuaries have a high $\mathrm{CO}_{2}$ flux $\left(\sim 0.25 \mathrm{Pg} \mathrm{C} \mathrm{y}^{-1}\right)$ between water and air, which is largely supported by the process of microbial decomposition and carbon fixation [3]. These microbiomes drive the estuarine biogeochemical processes of the elements for life [4]. They are powering the cycles of nutrients (e.g., carbon, nitrogen, phosphorus, and sulfur), with important impact on the composition of greenhouse gases in the atmosphere, the formation of algal blooms, and the integrity of estuarine ecosystems [5-7]. In fact, microbiomes are the foundation for the estuarine food chains and food webs [8-10], and their composition/distribution are important in the balance and stability of the entire estuary ecosystem.

Estuaries harbor a tremendous diversity of microbes. Due to the strong temporal and spatial gradients and surrounding land uses, the composition and distribution of the estuarine microbiomes are largely affected by human activities and climate/environmental changes [11-13]. Many studies have shown that spatiotemporal environmental variations enrich certain microbial taxa to dominate in estuaries, including the Chesapeake Bay [14], Delaware Bay [15], Sacramento-San Joaquin River Delta [16], Pearl Estuary [17], and Columbia River estuary [18]. In response to strong physical, chemical and biological gradients, estuarine microbiomes exhibit pronounced fluctuations in production and biomass [19, 20], as well as community composition [11, 21, 22]. It has also been shown that different microbial groups respond differently to spatiotemporal variations [11, 23]. These earlier studies provide important insights into the impact of spatiotemporal variations and other disturbances (such as anthropogenic pressures) on estuarine microbial community structure and dynamics. More interestingly, the spatial and temporal succession patterns are repeatable and predictable on an annual base [24-28], suggesting the microbial population dynamics are closely interrelating to their ambient aquatic environments. Annual selection pressure driven by environmental forcing has, through the induction of recurrent patterns in resource availability, predator-prey dynamics and microbial interactions, allowed for the assemblage of largely stable and resilient microbial communities [28]. Annually reoccurring patterns indicate that different microbiomes indeed have distinct niches with limited redundancy, otherwise different combinations of microbiomes would appear under the same conditions and prediction can be difficult [26]. These annually reoccurring assemblages and structure of microbiomes suggest their potential ecosystem functions (e.g., autotrophic or heterotrophic microbial production) are specialized and annually repeatable as well [24].

Functional traits of microbiomes are products of multiple populations within communities rather than those of a single population [29], and therefore correlations and associations among microbial taxa are critical to maintain ecosystem integrity and microbiome functionality. Different species or populations interact with each other to form complicated networks through various types of interactions, such as predation, competition and mutualism [30,

31]. Theoretical studies showed that communities in which a large proportion of members connected through positive links (i.e. positive correlations) are deemed to be unstable; in such communities, members may respond in tandem to environmental fluctuations, resulting in positive feedback and co-oscillation [31]. In contrast, ecological networks with compartmentalization and presence of negative relations could increase the stability of networks under disturbances [31-33]. For instance, high proportion of negative links could better balance the asynchronous dynamics and therefore stabilize co-oscillation in communities and promote stability of networks [31]. Further, modeling studies show that increasing strength of a few key correlations within a food web can destabilize trophic cascades, such as the "gatekeepers" [34], as removal of influencers causes a network to fragmentation [35]. In general, microbial associations (networks) play critical roles in maintaining community states, ecological niches and function distribution in the context of the microbiome [36].

Co-occurrence networks can reveal information on associations within microbiomes and stability of whole communities [31, 36, 37]. It has been increasingly used to infer microbial potential interactions $[30,38]$ in soils [39, 40], oceans [41, 42], coastal waters [43], lakes [44, 45], rivers [46], and even in metabolic modeling [47] and genomic surveys [48]. These correlation-based networks show important details of community rules reflecting ecological processes such as cooperation and habitat partitioning, and could represent mathematical associations among different microbial groups [30, 37]. Despite co-occurrence networks have been studied in plenty of earlier studies, they rarely focused on the co-exist microbial networks and how these networks respond to 
spatiotemporal variations in estuarine environments such as the Chesapeake Bay (CB), the biggest estuary in North America with long residence time (up to 9 months) [49]. Taking into account the dynamic environmental gradients in CB such as temporal variations, freshwater runoffs and ocean water intrusion, microbial co-occurrence and their stability/resilience to environmental changes are critical in further understanding the CB ecosystem. As expected, not only the spatiotemporal variations have potentials to reorganize networks of associations between co-existing estuarine microbial taxa, the characteristics of these networks themselves can also determine the adaptability and resilience to environmental disturbances (such as agriculture and urban development). Nevertheless, there are still few detailed studies on microbial networks and their responses to environmental changes in typical estuarine environments [5053], and we need to address this important knowledge gap to deepen our understanding of estuarine microbiome ecology.

Recently, we have characterized the microbial community structures across both temporal and spatial scales in the CB, where planktonic microbiomes were collected across seven sampling stations (along spatial and salinity gradients) in four seasons over three consecutive years [54]. In this study, we constructed co-occurrence networks based on the 16S rRNA gene high-throughput sequences. Significant and strong correlations (including both positive and negative) were included in co-occurrence network analysis [55]. Due to previously described predominant seasonal and spatial variations in prokaryotic microbiome structure, networks from different seasons (temporal) and locations (spatial) were also constructed. In order to test the stability of co-occurrence networks, we assessed responsiveness of network fragmentation to removal of significant nodes (i.e., with highest betweenness centrality). Further, primary environmental drivers for microbial associations in the estuary were tested with multivariate regression tree analysis (MRT, [56]). Lastly, pathways that may explain how environmental gradients contribute to shaping estuarine microbiomes and their networks were identified and quantified with piecewise structural equation model (SEM, [57]). Based on all these analyses, quantitative associations of estuarine microbiome structures and the corresponding environmental drivers were proposed. This study provides the first snapshot on CB microbiome networks, the stability and adaptability, as well as their quantitative responses to environmental gradients, which are critical in improving our knowledge and understanding of the ecology of estuarine microbiomes.

\section{Methods}

\section{Sample collection and characterization}

Detailed description of sampling and environmental measurements have been described in previous studies [14, 54]. Briefly, surface water samples were collected from the CB at seven stations along the middle axis in February/March, May/June, August, and October from 2003 to 2005 (Fig. S1). Total 500 mL water samples (below $2 \mathrm{~m}$ ) were taken at each station and filtered immediately through $0.2 \mu \mathrm{m}$ Millipore polycarbonate filters (Millipore Corporation, Billerica, MA, USA). The filters were stored at $-20^{\circ} \mathrm{C}$ prior to DNA (deoxyribonucleic acid) extraction. Water temperature and salinity were recorded on board with a SeaBird 911 CTD (conductivity temperature depth, Sea-Bird Electronics, Washington, USA). Based on water temperature [14, 58], the samples collected in the Bay were divided into four seasons: winter (February and March), spring (May and June), summer (August) and autumn (October). Salinity and temperature were measured on site during the sampling cruises, but other abiotic data were obtained from the Chesapeake Bay Program's (CBP) Water Quality Database (https://www.chesapeakebay.net/what/downloads/cbp_water_quality_database_1984_present). These parameters were sampled/measured in the same month and close to the sampling days, including total organic nitrogen (TON), ammonium, nitrate, Chl $a$ (Chlorophyll a), dissolved organic phosphorus (DOP), orthophosphate phosphorus (OP/phosphate), total suspended solids (TSS), particulate carbon (PC), and turbidity (measured as Secchi depth). Although the CBP stations do not have the exact same coordinates as our stations, they are reasonably close to our sampling sites (within 2 to $3 \mathrm{~km}$ ).

\section{DNA extraction and sequencing analysis}

Environmental DNA extraction followed the protocol described previously [59]. Dried environmental DNA pellets were lyophilized and archived in -80 ${ }^{\circ} \mathrm{C}$ for long time storage. The V4 region of the 16S rRNA (ribosomal ribonucleic acid) genes were amplified using the primers 515f (5'-GTGYCAGCMGCCGCGGTAA-3') and 806r (5'-GGACTACNVGGGTWTCTAAT-3'), and sequenced on an Illumina Nova6000 platform (paired-end 250-bp mode) following the manufacturer's guidelines. High-throughput sequences were processed and analyzed with QIIME (Quantitative Insights Into Microbial Ecology) 2_2019.1 [60]. DNA concentration and quality, sequencing depth, quality of raw reads and further results all demonstrated that the samples are qualified for sequencing analysis. Taxonomy annotation of these qualified sequences were based on $99 \%$ similarity to references in the Silva classifier 132-99-515-806 databases. The sequenced dataset contained 15,439,352 sequences constituting 4,865 amplicon sequence variants (ASVs) after removing the chloroplast and unidentified reads. These ASVs were rarified to 85,000 sequences per sample for downstream analyses. To avoid potentially erroneous sequences and improve interpretability of the dataset, we filtered out the ASVs (1) presented in fewer than $20 \%$ samples, and (2) with summed relative abundance less than $0.5 \%$ in each particular network inference [46]. After this sequence processing, the final dataset consisted of $6,002,328$ sequences which constituted 780 ASVs for further co-occurrence network analysis. Raw sequence data is available at the GenBank database under the accession number SRX6973110-SRX6973185.

\section{Co-occurrence network analysis}

Three categories of co-occurrence networks were constructed: (1) networks across all samples to explore overall microbial associations at spatiotemporal scales; (2) networks in four different seasons based on water temperature; and (3) networks in upper and lower Bay. Salinities were significantly different $(P<0.01)$ between the upper Bay (samples from station 908, 845, and 818) and lower Bay (samples from station 707, 724, and 744). In order to compare the networks across season and space, they were nomalized at 18 samples and 340 ASVs for seasonal networks and 31 samples and 384 ASVs for upper and lower Bay networks respectively, by using the function "sample" in R before network construction. Network enhancement was implemetated by the package 'neten', and applied to remove the fake linkes [61]. Microbial networks were constructed at ASV level. All network constructions were performed in R (version 4.1.0) and corresponding codes were adapted from GitHub (https://github.com/ryanjw/co-occurrence) [55]. The false discovery rate was estimated and corrected by the package 'fdrtool'. Only microbial families with statistically significant $(P<0.01, \mathrm{Q}$-value $<0.05)$ and robust (spearman's correlation coefficient $>$ |0.6| before and after network enhancement analysis) correlations [40] were included to present both of positive and negative relations in network analyses. In order to test if networks were significantly clustered, random networks were also constructed and compared following RJ Williams, A Howe and KS Hofmockel [55]. 
Network visualization and topological analysis were carried out in Gephi (version 0.9.2). The nodes with high degree or high betweenness centrality are crucial for ecological network structure and persistence because they literally hold the network together [62-65]. The topological properties of microbial networks were calculated with indexes including component, average clustering coefficient, modularity, network diameter, graph density, average path length, proportions of positive and negative correlations, and network fragmentation ( $f$ ) [66-69]. Because microbial groups contribute differently to the network structures, the distribution of node-normalized degree (the number of connections a node has standardized by the total number of connections in the network) in each network was also examined. Microbial networks were also analyzed at the family level in order to mine universal microbial patterns.

Network stability were primarily characterized based on network topology such as number of components, modularity, proportion of negative correlations, and network fragmentation $(f)$ (Table S1). The $f$ was calculated as the ratio of the number of disconnected subgraphs (CL) to the overall number of nodes $(M)$ in each network as $\log (\mathrm{CL}) / \log (N)$ [46]. The $f$ ranges from 0 to 1 , and closer to 1 represents more fragmented and less stable networks. Loss of "gatekeepers" (i.e., nodes with high betweenness centrality) contributes disproportionately to network fragmentation, suggesting high fragility of these networks upon selective removal of species $[46,70]$. Therefore, the network stability was further tested by recording $f$ upon iteratively removing the top 10 nodes with the most abundance, betweenness centrality, and degree $[46,71]$. In addition, the correlation between node-normalized degree and betweenness centrality were explored: higher correlations indicated more stable networks because when a network containing more nodes with both high betweenness centrality and high degrees, it is more likely to have alternative nodes to hold the network together when certain nodes with high betweenness centrality were lost [36]. Based on all these network parameters, the stability of microbial co-occurrence was evaluated and compared across time and space.

\section{Multivariate regression tree (MRT) analysis}

To determine how the $\mathrm{CB}$ microbiomes respond to spatiotemporal variations, multivariate regression tree analysis (MRT, [72]) was used to evaluate the hierarchical effect of environmental changes on the microbiomes. It was determined and generated by the R package "mvpart" (R version 3.6.1), and the divisions in the MRT were determined by cross-validation.

\section{Structural equation modeling (SEM)}

Piecewise structural equation model (SEM) was used to analyze hypothetical pathways that may explain how spatiotemporal variations in the Bay shaped the composition, distribution and associations of microbiomes [73]. Compared to redundancy analysis that has been applied in our earlier papers [54], it allowed us to partition direct and indirect effects of each environmental variable relative to major bacterioplankton groups and estimate the strength of multiple effects. The first step was to build a priori model based on the known effects and relationships among environmental factors and dynamics of prokaryotic microbial communities. From MRT analysis results, we identified temperature, salinity and TSS as the primary driving factors. These three environmental variables covered seasonal variations and influence from freshwater or ocean input, and therefore affected microbial associations through changing Chl $a$, nutrient availability (e.g. N, P), and PC. Then, a maximum likelihood goodness-of-fit test was used in model fitting and a non-significant $P$ value indicates a well-fit model [74]. In comparison to traditional SEM, piecewise SEMs are less restricted by the number of links per sample size and Fisher's $C$ can be used as the goodness-of-fit indicator [57, 75]. Piecewise SEM was performed in R (version 3.6.1) by using the piecewiseSEM package [57].

\section{Results}

\section{Microbial networks across all samples}

The correlation-based co-occurrence networks including all samples were constructed and visualized based on relative abundance, degree, and betweenness centrality, respectively (Fig. 1). The resulting CB microbiome networks consisted of 387 nodes (prokaryotic microbial taxa) and 4130 edges (significant and robust associations between taxa; average degree 21.3) (Fig. 1). Topological properties commonly used in network analysis were calculated and listed in Table 1. The average network path length between all pairs of nodes was 3.12 edges with a diameter (longest distance) of 8 edges. In total, the network contained 3 components (those separated subgraphs in a network) and 7 clusters (a group of nodes with higher number of within-cluster edges than betweencluster edges). The clustering coefficient (the degree that nodes tend to cluster together) was 0.509 . These clusters were affiliated to almost all major prokaryotic microbial groups in the Bay, and also showed both positive and negative relations with many nodes in other clusters. Plentiful prokaryotic microbial groups clustered into one cluster with both positive and negative relations means that microbial associations were diverse and complex in the Bay. These clusters revealed the potential ecological relationships among prokaryotic microbiomes in the Bay and how they organized by niches in the estuarine ecosystem with habitat partitioning/sharing. Overall, the microbiome network in CB was comprised of highly interconnected taxa, formed a clustered topology, and contained 'small-world' properties (nodes are more connected) based on the modularity statistical analysis in Gephi.

Top ten ASVs ranked with averaged abundance, degree (number of connections) and betweenness centrality (how well a node is interacting simultaneously with different compartments of the network, potentially "gatekeepers") were selected and listed in Table S2. The high-degree nodes (i.e., hub species that have the highest degree [36]) belonged to Gammaproteobacteria (Alcanivorax and SAR86 clade), Bacteroidetes (Rhodothermaceae and Ignavibacteria), Alphaproteobacteria (AEGEAN-169 marine group, SAR116 clade and Sneathiellaceae), Deltaproteobacteria (OM27 clade), Planctomycetes (Pla3 lineage), and Betaproteobacteria (Nitrosomonadaceae) (Table S2). The nodes with high betweenness centrality belonged to Actinobacteria (Microbacteriaceae and Sporichthyaceae), Cyanobacteria (Cyanobium PCC-6307), Alphaproteobacteria (Pseudorhodobacter), Gammaproteobacteria (Ectothiorhodospiraceae and OM60(NOR5) clade), Betaproteobacteria (Polynucleobacter), Planctomycetes (Pirellula), Bacteroidetes (NS11-12 marine group and Fluviicola) (Table S2). These nodes were crucial for microbial network structure and persistence in CB because they literally hold the network together. In contrast, the most abundant bacterial ASVs (e.g., SAR11 clade, Saprospiraceae and Actinomarinaceae) are distinct from hub species and those groups with high betweenness centrality (Table S2). Similar patterns were also observed at the family level (Fig. S2).

\section{Microbial co-occurrence in different seasons}


Distinct seasonal networks were obtained after applying the identical thresholds as described above (Fig. 2 and Table 1). For clarity and brevity, only networks based on microbial connections (degree) were included (Fig. 2). The seasonal networks were comprised of highly connected microbial taxa and densely connected groups formed a clustered topology with comparable seasonal variations (Fig. 2). The modularity indexes across four seasons were all greater than 0.4 suggesting modular structures especially in the autumn (Table 1) [76]. Within a co-occurrence network, modules are densely correlated microbial groups governed by ecological processes such as conserved inter-species communications, and therefore are good indicators for habitat partitioning/preferences [67]. The number of components in the network of each season was 1 except it's 2 in the winter, and the amount of clusters was the same across seasons (6), except the winter network was 9 (Table 1). The summer network consisted of the biggest number of edges $(3,983)$ with average degree 23.6 (Table 1$)$. Although the network in winter contained the lowest number of nodes (331), it had the high average degree (20.7) with 3,430 edges compared to spring network (Table 1). In addition, the network in summer contained the highest graph density, shortest path length and high clustering coefficient (Table 1). All these characteristics indicated that summer microbiomes in CB were more closely associated and correlated.

The nodes with high degree/betweenness centrality were different for each season (Table S3). For example, Betaproteobacteria (Burkholderiaceae) were ranked the top 10 nodes with high degrees in autumn, but it didn't occur in the list of top 10 nodes for other three seasons (Table S3). Planctomycetes (CL5003 and Pirellula) and Kiritimatiellaeota (WCHB1-41) were only included in the top 10 nodes with high degrees in the network of winter, and Verrucomicrobia (Cephaloticoccus) were only ranked in the top 10 nodes with high degrees in the network of spring (Table S3). Different nodes affiliated to Actinobacteria were included in the top 10 nodes with high degrees in the network of four seasons ( 3 in winter, 0 in spring, 5 in summer, and 1 in autumn). These specific and distinct microbial taxa played various roles in structuring the ecological networks for each season based on the results at both ASV (Fig. 2) and family (Fig. S3) levels.

\section{Microbial co-occurrence in upper Bay vs. lower Bay}

Similarly for clarity and brevity, only networks based on microbial connections (degree) were shown (Fig. 3). Networks for upper and lower Bay were different regarding size and topology (Fig. 3 and Table 1). The network in lower Bay consisted of 376 nodes and 5, 012 edges (average degree of 26.7), while the network in upper Bay was consisted of 367 nodes and 4, 526 edges (average degree of 24.7) (Table 1). The amount of average path length and graph density means the network of upper Bay was more split compared to the lower Bay (Table 1). Compared to upper Bay, more microbial taxa and more pronounced associations occurred in lower Bay with higher graph density (Table 1).

The top 10 ranked microbial taxa based on degrees and betweeenness ranking were showed in the Table S4. In upper Bay, the nodes with high-degree were belonged to Gammaproteobacteria (Alcanivorax and OM60(NOR5) clade), Alphaproteobacteria (SAR116 clade, Parvibaculaceae and Sneathiellaceae), Bacteroidetes (Rhodothermaceae), Verrucomicrobia (Pedosphaeraceae), and Deltaproteobacteria (SAR324 cluster) (Table S4). In contrast, those nodes with high degree in the lower Bay were affiliated with Gammaproteobacteria (Alcanivorax, SAR86 clade and an uncultured Gammaproteobacteria), Alphaproteobacteria (Rhodospirillales, SAR116 clade and Sneathiellaceae and AEGEAN-169 marine group), and Deltaproteobacteria (SAR324 clade(Marine group B)) (Table S4). Similarly, those nodes with high betweenness centrality were also distinct between upper and lower Bay (Table S4). Same patterns of microbial networks across space were also observed at the family level. Overall, our results demonstrated that the microbial networks differed between upper Bay and lower Bay, and different microbial taxa contributed to the modularity and stability of the microbiome network structure across space.

\section{Stability of estuarine microbiome networks}

In addition to comparing the topological properties listed in Table 1, we analyzed the responsiveness of network fragmentation ( $f$ ) to removal of top 10 nodes with highest relative abundance, degree and betweenness centrality, respectively. Compared to the original network $(f=0.18$, number of components $=3)$, the $f$ and the number of components changed more dramatically in the treatment of removing 10 nodes with highest betweenness centrality $(f=0.27$, number of components $=5)$ compared to the treatment of removing 10 nodes with the highest relative abundance $(f=0.23$, number of components $=4)$ or degree $(f=0.19$, number of components $=3$ ) (Table 1). Similar results were also observed in modularity (Table 1), suggesting removal of the nodes with high betweenness centrality could much strongly undermine the stability and persistence of the prokaryotic microbial network than removal of the most abundant/highest degree nodes. Further, the degree and betweenness centrality of abundant groups (top 10, 20 and 50, respectively) were significantly different compared to those ASVs with high degree or betweenness centrality $(P<0.01)$, respectively. Combined with the results of Figure 1, our results clearly showed that the most abundant prokaryotic microbial groups are neither necessarily the hub species nor with high betweenness centrality in $\mathrm{CB}$. Compared to the abundant taxa, the minor/rare groups with high degree or betweenness centrality contribute greatly to the stability of prokaryotic microbial co-occurrence in the Bay.

We further analyzed the stepwise responsiveness of co-occurrence network fragmentation to removal of the top 10 nodes with highest abundance/degree/betweenness centrality for seasonal and spatial microbial networks. Removing the low abundance taxa (but with high betweenness centrality) greatly reduced the stability of the co-occurrent networks across time and space than the removal of abundant ASVs ( $P<0.01)$ (Table S5). Thus, the contribution of rare taxa to network stability has been further demonstrated in microbial networks across time and space (Fig. 4, and Table S5). $f$ started an increase from the second round in winter, and then $f$ increased from the sixth and nineth round. The $f$ values in winter were significantly higher compared to those of spring, summer and autumn $(P<0.01)$ (Fig. 4). Similarly, the $f$ values in spring were significantly higher compared to those of summer and autumn $(P<0.01)$. Also the number of components increased from 2 to 6 in the network of winter ( 2 for the spring and 1 for summer and autumn) after the removal processes (Fig. 4 and Table S5). but it maintained 0 even after 10 removals in summer (Fig. 4 and Table S5). These results further elaborate that the stability of microbiome networks varied across seasons in the $\mathrm{CB}$, where microbial co-occurrence were more stable and resilient in warm seasons (summer) than those in cold season (especially winter). Similarly, microbial networks showed higher stability in lower Bay than upper Bay (Fig. 4 and Table S5): the number of components $(f)$, and $f(0.1179)$ increased greatly in the upper Bay compared to the original network while the network properties in the lower Bay changed little after the removal of top 10 nodes (Table S5).

Seasonal networks contained high percentage of significant negative correlations (15.34\%-18.65\%) than spatial ones (upper Bay,7.60\%; lower Bay, 11.15\%) (Table 1). The high proportion of negative correlations in each season could increase the stability and persistence of microbial network. Significant

Page 5/18 
correlations between node-normalized degree and betweenness centrality were observed in each spatial and temporal network based on spearman-correlation analysis (Fig. 5). Further, Monte Carlo simulation results showed that the correlations ( $\rho$ values) were significantly different $(P<0.01)$ in microbial networks across time and space: Summer>Autumn>Spring>Winter; and lower Bay>upper Bay. The difference suggested that the nodes with high betweenness centrality ("gatekeepers") also comprised high degree (i.e., hub species) in warm seasons compared to those in cold seasons, and in lower Bay compared to those in upper Bay. Therefore, once the "gatekeepers" were removed due to disturbances, likely they could be replaced by other hub species, which would connect different compartments and hold the network together. This can help to maintain the stability and enhance the anti-interference ability of the network. In addition, high modularity was observed across seasons (0.404-0.496) compared to spatial scales $(0.335-0.363)(P=0.03)($ Table 1$)$. Modules could be used to visualize different niches in microbial networks and thus habitat partitioning/preferences strongly existed under different seasons compared to spatial variations in the $\mathrm{CB}$ with long residence time.

Overall, the stability of microbial co-occurrence networks were tested and verified through comparisons of microbial networks across spatial and temporal scales. Based on our results of fragmentations, proportion of negative correlations, the correlation between node-normalized degree and betweenness centrality, and modularity, this study showed that the structure, properties, and stability of prokaryotic microbial networks were distinct across spatiotemporal variations. Microbial co-occurrence networks in warm seasons (especially summer) were more stable than cold seasons (i.e., winter), and the lower Bay was more stable than the upper Bay.

\section{Associations with environmental factors}

To further explore the effect of environmental variations on microbial networks, microbial network ASVs and their associated environmental factors were included in the further network analysis (Fig. 6). Significant correlations between environmental factors and microbial taxa were visualized by network and clusters (Fig. 6). The majority of taxa (nodes) in the same cluster may have close relationships or share similar ecological niches (i.e., co-occurrence). Seasonal changes (temperature), salinity gradients and TSS (and turbidity) levels were significantly correlated to nutrient availability (nitrogen, phosphorus), $\mathrm{PC}$, and $\mathrm{Chl}$ a concentrations in the Bay, and all of these factors were responsible for separation and topology of microbial networks across season and space (Fig. 1, 2, 3 and 6). Total 163 taxa were identified closely associated with temperature while 121 strongly responded to salinity. Meanwhile, TSS, nutrient availability (mainly $\mathrm{N}$ and $\mathrm{P}$ ), PC, and Chl a also played significant roles in microbial distribution and co-occurrence (Fig. 6).

MRT results confirmed that temperature, salinity, and TSS were ranked the top drivers to shape spatiotemporal variations of microbiomes in CB (Fig. S5). In summary, the accumulative variance explained by temperature, TSS and salinity were $39.2 \%, 12.6 \%$, and $4.9 \%$ respectively (Fig. S5). Based on these results, relationships between microbiomes and major environmental variations were further assessed by piecewise SEM (Fig. 7). Due to the limited space, only key correspondences were highlighted in the Fig. 7, and the others and co-varied relations were included in the supplemental Table S6. We found that temperature, TSS and salinity contributed greatly to the distribution and associations of microbial groups and also strongly affected other environmental parameters including nutrient availability, PC and $\mathrm{Chl}$ a (Fig. 7). For instance, increase of temperature was associated with decreased Alphaproteobacteria, Betaproteobacteria and Bacteroidetes (negative effect), and increased abundance of Deltaproteobacteria, Planctomycetes, Gemmatimonadetes and Cyanobacteria (positive effect) (Fig. 7). Through correlations with nitrate and DOP, the temperature also affected other microbial groups such as Cyanobacteria, Actinobacteria and Chloroflexi (Fig. 7). Salinity gradient in the Bay was significantly linked to Actinobacteria, Cyanobacteria, Verrucomicrobia, Deltaproteobacteria and Chlamydiae, while it influenced Chloroflexi, Verrucomicrobia, Firmicutes through reducing the availability of nitrate, ammonium, Chl $a$, and OP (Fig. 7). These direct and indirect effect of environmental variables relative to major bacterioplankton groups in the Bay and the strength of multiple effects were analized by piecewise SEM. Along with PC, ammonium and TON, TSS impacted several groups including Deltaproteobacteria, Chlamydiae, Chloroflexi, Firmicutes and Patescibacteria (Fig. 7). In general, our results clearly showed how spatial and temporal variations of environmental factors affected estuarine microbiome association and co-occurrence (networks) (Fig. S3, 6, 7).

\section{Discussion}

The estuarine microbiome networks are comprised of highly interconnected taxa, formed clustered topologies, and thus contained 'small-world' properties [77]. Among the interconnected taxa, the abundant microorganisms contribute greatly to the biomass, nutrient cycling, and primary production [11, 78, 79]. However, the most abundant microbial groups are not those taxa that hold the network together, such as "hub species" or "gatekeepers" at both ASV and family levels (Fig. 1 and S2). Thus, abundant taxa may not be necessarily critical to the prokaryotic microbial network structure or their stability (Table 1 and S2). In this study, the hub species and gatekeepers are relatively low in abundance or belong to rare species (Table S2), but they play fundamental roles in network persistence and contribute greatly to the stability and resilience of these taxa-taxa networks [80]. Recent studies have increasingly emphasized the ecological importance of the rare biosphere, because rare taxa can include more metabolically active microorganisms than abundant taxa (as measured by RNA to DNA ratios), and they may be keystone species in regulating the functioning of aquatic environments [81, 82]. In addition, the rare microbes have been shown to fulfill essential functions associated with nutrient cycling, and may enhance functionality of the abundant microbes [83]. For example, it has been demonstrated that rare species offer the required gene pool to catalyze complex degradation processes of organic compounds, and some pollutants are often degraded by species falling below the detection limit in pristine samples [84].

Our results further corroborated the significance of "hub species" and "gatekeepers" via stability testing with removal processes. The responsiveness of network fragmentation to removal of nodes with highest betweenness centrality provide important insights into the susceptibility of prokaryotic microbial networks to disturbance [46]. Our results suggest that the loss of those potential "gatekeepers" contributes disproportionately to network fragmentation, which essentially agrees with earlier reports on food webs and mutualistic networks showing high fragility/susceptibility upon selective removal of taxa [33, 70, 85]. Sequencing data allowed us identify that potential "gatekeepers" were affiliated with Actinobacteria (Sporichthyaceae, Microbacteriaceae, CL500-29 marine group and PeM15), Betaproteobacteria (Polynucleobacter), Alphaproteobacteria (Sphingorhabdus), Bacteroidetes (Cryomorphaceae), Planctomycetes (Pirellula), and Gammaproteobacteria (Legionella). These taxa had highest betweenness centrality values (937-1943) and were consistently present in the 
major component of the co-occurrence networks. The loss of "gatekeepers" may adversely affect the robustness and resistance of microbiome structure and associations [33, 70, 85]. Similarly, strongly interacting species (i.e., "hub species") are important to CB microbial communities, and they were shown to be able to steer microbiome ecosystems towards certain community types [86]. Additionally, as part of the microbial "seed bank", rare taxa (including these high degree/betweenness centrality but low abundance species) can potentially drive ecosystem responses to environmental changes and become dominant under favorable conditions [87], therefore providing a mechanism for community persistence and stability [88].

Similar to microbiome structures [14,54], microbial co-occurrence networks showed strong temporal and spatial patterns with distinct property and stability (Fig. 2-5, Fig S2-S4 and Table 1). Our results showed that consistent patterns of microbial networks were observed at different taxonomic levels. These differences are likely due to strong gradients in seasonality, salinity, nutrient availability, and other causal environmental factors [11, 18, 89, 90]. CB, the largest estuary in northeast America, experience typical seasonal changes and constant freshwater/oceanic water input and exchange. The dynamic estuarine gradients lead to large variations in bulk bacterial production and biomass [19, 20], and community composition [11, 22], and subsequently affecting the property and stability of microbial networks (this study, Fig. 2-6 and Table 1; [52, 91, 92]).

Warm season microbial networks revealed high number of edges, high average degree, hign graph density, low number of components and clusters, low fragmentation, high modularity, and high number of negative links. Stronger correlations between node-normalized degree and betweenness centrality and less variability of fragmentation after removing the potential 10 "gatekeepers" were also observed in the networks for summer and autumn (Fig. 4 and Table 1). These results indicated that microbial networks were more stable during warm seasons compared to those in winter and spring. Microbial co-occurrence affected by temporal variations were also found in Alaska Beaufort Sea coast [51], the San Pedro Ocean Time-series station [91], and the Lake Mendota [93]. The higher number of nodes in the co-occurrence networks of warm season agrees with the previously reported high microbial diversity in the Bay [14,54]. High biodiversity is able to promote co-occurrence between microbial communities [94], and these biotic associations including competition, are commonly thought to increase co-occurrence in microbial networks as they refer to common resources and environmental conditions [30, 95, 96]. In addition, increase in grazer richness has a positive effect on the bacterial richness and evenness [97], stemming primarily from the widespread distribution of resources and then resulting in ecological niche complementarity [98-100]. Finally, this stability is also due to long residence time and relatively high growth rate (and mortality) of different microbial populations [20,90], which allows estuarine bacteria overwhelm those allochthonous populations from marine or freshwater [101]. Therefore, stable prokaryotic microbial networks in warm season in the Bay may arise from a better balance of the microbial associations (e.g., mutual, competitive and prey) and nutrient availability during summer and autumn than winter and spring [11, 20, 102]. In contrast, microbial associations in cold seasons contained high fragmentation and it may be reinforced by stronger nutrient limitations and lower growth rates (due to low temperature) [20].

Compared to the upper Bay, the network in the lower Bay was more connected with more negative correlations (Fig. 3, Table 1). High percentage of negative links in the networks could stabilize co-oscillation within microbial communities and increase network stability [31]. A strong association between nodenormalized degree and betweenness centrality and the less variability of fragmentation after removing potential "gatekeeper" nodes were also observed in the network of lower Bay (Fig. 4, 5). Our results suggested that the stability of prokaryotic microbial network was higher in the lower Bay compared to the upper Bay. The stability difference between upper and lower Bay could be due to the disturbance and interference from freshwater vs. oceanic water. Similar environmental variations were also found in many other estuaries, and spatial variation also could affect bacterial associations, including Ems estuary [92], Hangzhou Bay [43,53] and Pearl River Estuary [104]. River input, land runoff, suspended particles/turbidity, and accompanied nutrients availability are all pulsating with strong seasonal/inter-annual variations and uncertain patterns in the upper Bay. Conversely, salty water intrusion from the North Atlantic Ocean can be relatively consistent, and we thus hypothesize that less temporal disturbances from the ocean contribute to higher stability of microbial networks in lower Bay compared to the upper Bay.

Estuarine microbiomes continuously experience environmental perturbations including pulse, press and environmental stochasticity [105]. This study was not originally designed and intended to investigate community recovery after defined perturbations such as pulse (e.g., floods) or press (lasting disturbances such as climate changes), therefore the results are more reflecting the ecological stability of microbiome correlations under the perturbation of environmental stochasticity [105]. Ecological stability is a multidimensional concept that captures different aspects of the dynamics of the ecosystem and its response to perturbations [106]. Pimm (1984) summarized five components of ecological stability that are in common use: asymptotic stability, variability, persistence, resistance, and resilience [107]. In this study, multiple metrics in network topology including the number of components, modularity, negative correlations, fragmentation as well as the correspondence between node-normalized degree and betweenness centrality are used to characterize the asymptotic stability and variability, both of which indicate higher network stability in warm season than cold seasons, and lower Bay than upper Bay. However, due to the high correlations between metrics used, it is difficult to propose a single best way of selecting metric(s) in evaluating the independent stability components. For instance, negative correlations between metrics would suggest trade-offs, although they seem to be rare exceptions in complex trophic communities [106]. Further, the choice of the metrics always depends on the system studied and practical constraints, therefore measuring more stability metrics with deep and hierarchical analyses and/or explained variance analyses can help making informed choices and improve our understanding of the full-picture of microbial stability in the Bay for the future studies.

Due to the continuous environmental perturbations, the estuarine microbiomes and their distribution are a comprehensive output of the bio-associations between microbial populations and the response to the surrounding environmental gradients. Our results show that shifts of environmental factors (including temperature, salinity, TSS, nitrogen, phosphorus, and PC) have strong effect on microbial community structure and networks. The shifts within the spatiotemporal variations seem to favor strong co-occurrence patterns (lower fragmentation and higher stability) of prokaryotic microbial associations, implying elevated biotic co-occurrence or species sorting strongly mediated by the local environment [96, 109]. Physiologic predisposition and nutritional tolerance of microbiomes tend to maintain stable communities inter-annually during certain seasons [11, 25, 110]. Focusing on the identified prokaryotic microbial networks and their responses to environmental variations could provide us valuable insights into the microbiome adaptation and habitat partitioning/preferences in the Bay across seasonal changes and spatial gradients [30,67, 111]. In addition, co-occurrence networks reveal critical information on co-oscillation between microbial taxa and also the stability of these involved communities in the Bay [30, 36, 111]. Therefore, changes in estuarine 
microbial networks resulting from disturbances provide a potential to examine the legacy effect on estuarine microbiome population structure, ecological function (e.g., contribution to primary productivity, food webs and economical sustainability) and its vulnerability to future disturbances, such as anthropogenic influence (e.g., eutrophication, contamination and damming) and climate change (e.g., drought and flood) [11, 31, 111].

To the best of our knowledge, this is the first systematic and thorough study of the microbiome co-occurrence associations, their stability, and the corresponding environmental factors in an estuary with long residence time, the Chesapeake Bay. There are some limiations and caveates in this study. For instance, most environmental parameters in the current study were not from the on-site samples that collected during the cruises. Instead, we used the data from the long term Chesapeake Bay Program's (CBP) Water Quality Database

(https://www.chesapeakebay.net/what/downloads/cbp_water_quality_database_1984_present). Plenty of previous studies and our own observations have shown clear and repeatable spatiotemporal patterns in the Bay [112-114]. These stable patterns are reoccurring annually and spatially, and therefore the CBP data closest to our sampling sites and dates were used in our analysis. In addition to the environmental gradients included in this study, many other abiotic or biotic associations also play critical roles in microbiome composition and distribution. For example, grazing and viral lysis are important factors that may affect the associations and stability of estuarine microorganisms [115-117], which deserve future investigations. Currently, we are analyzing the structure of microeukaryotic communities in the Bay, which may provide further information on primary producers and their interactions with other estuarine microbiomes. All in all, examining the natural spatiotemporal changes and stability of microbial networks as well as their interactions with other organisms is essential to strengthen the understanding of estuarine ecosystem processes.

\section{Conclusions}

This study shows that environmental variations dictate stable and resilient estuarine microbiome associations in the Chesapeake Bay. Compared to dominant taxa, rare groups (e.g., hub species and gatekeepers) contribute greatly to the network topology and stability. Microbiomes in warm seasons exhibit stronger and more interactive networks than cold seasons, while the microbial network in the lower Bay is more stable than the upper Bay. The freshwater input from upstream brings pulsating and uncertain factors to microbial populations in CB, such as nutrients, particles, and microorganisms from terrestrial and freshwater environments. In contrast, the intrusion of seawater at the lower Bay is relatively mild and consistent so that the Bay microbiomes are able to adapt to the subsequent impact. Our piecewise structure equation model (SEM) unraveled that spatiotemporal variations (i.e., temperature, salinity, TSS, nutrient availability) are the primary driving factors for microbiome structures and co-occurrence, and these environmental gradients manipulate the stability and tolerance/susceptibility of estuarine microbiota. This work shows, for the first time, dynamics of microbiome networks and their responses to environmental gradients in a typical estuarine environment with long residence time. Given such dynamic environmental gradients, stable and persistent microbiome networks suggest that biotic associations play a central role in maintaining integrity and resilience of estuarine microbiomes.

\section{Abbreviations}

\section{CB Chesapeake Bay}

MRT multivariate regression tree

SEM structural equation model

DNA deoxyribonucleic acid

CTD conductivity temperature depth

CBP Chesapeake Bay Program

TON total organic nitrogen

Chl a Chlorophyll a

DOP dissolved organic phosphorus

OP orthophosphate phosphorus

TSS total suspended solids

PC particulate carbon

rRNA ribosomal ribonucleic acid

Qiime Quantitative insights Into Microbial Ecology

ASVs amplicon sequence variants

fragmentation

$\mathrm{CL}$ disconnected subgraphs

$N$ overall number of nodes 
ANOSIM analysis of similarities

\section{Declarations}

Ethics approval and consent to participate: Not applicable

Consent for publication: Not applicable

Availability of data and material: All data generated or analyzed during this study are included in this published article and its supplementary information files. The high throughput sequencing data for the Chesapeake Bay microbiomes are available through the GenBank data database under the accession numbers SRX6973110-SRX6973185.

Competing interests: The authors declare that they have no competing interests.

Funding: The sampling effort was supported by NSF MCB-0132070, MCB-0238515, and MCB-0537041. This study was supported by a Visiting Professor Program at Southern University of Science and Technology, and Endowment Fund from Stroud Water Research Center to Jinjun Kan. Chuanlun Zhang's Participation in this project was supported by the National Natural Science Foundation of China (91851210 and 41530105 ), the Shenzhen Key Laboratory of Marine Archaea Geo-Omics, Southern University of Science and Technology (ZDSYS201802081843490), and the Southern Marine Science and Engineering Guangdong Laboratory (Guangzhou) (K19313901).

Authors' contributions: HW, FC and JK designed the study. HW and JK analyzed and interpreted the data, and HW, FC, and JK discussed the results. HW, FC, $\mathrm{CZ}, \mathrm{MW}$ and JK contributed to writing and editing the manuscript. All authors read and approved the final manuscript.

Acknowledgements: Not applicable

\section{References}

1. Whitman WB, Coleman DC, Wiebe WJ. Prokaryotes: the unseen majority. Proc Natl Acad Sci U S A. 1998;95:6578-83.

2. Whittaker RH, Likens GE. Primary production: the biosphere and man. Hum Ecol. 1973;1:357-69.

3. Cai W-J. Estuarine and coastal ocean carbon paradox: $\mathrm{CO}_{2}$ sinks or sites of terrestrial carbon incineration? Annu Rev Mar Sci. 2011;3:123-45.

4. Falkowski PG, Fenchel T, Delong EF. The microbial engines that drive earth's biogeochemical cycles. Science. 2008;320:1034-9.

5. Azam F, Malfatti F. Microbial structuring of marine ecosystems. Nat Rev Microbiol. 2007;5:782-91.

6. Moran MA, Reisch CR, Kiene RP, Whitman WB. Genomic insights into bacterial DMSP transformations. Annu Rev Mar Sci. $2012 ; 4: 523$.

7. Zehr JP, Kudela RM. Nitrogen cycle of the open ocean: from genes to ecosystems. Annu Rev Mar Sci. 2011;3:197-225.

8. Bauer JE, Cai W-J, Raymond PA, Bianchi TS, Hopkinson CS, Regnier PAG. The changing carbon cycle of the coastal ocean. Nature. 2013;504:61-70.

9. Madsen EL. Microorganisms and their roles in fundamental biogeochemical cycles. Curr Opin Biotechnol. 2011;22:456-64.

10. Liu T, Zhang AN, Wang J, Liu S, Jiang X, Dang C, et al. Integrated biogeography of planktonic and sedimentary bacterial communities in the Yangtze River. Microbiome. 2018;6:16. doi:10.1186/s40168-017-0388-x.

11. Fuhrman JA, Cram JA, Needham DM. Marine microbial community dynamics and their ecological interpretation. Nat Rev Microbiol. 2015;13:133-46.

12. Boyd PW, Cornwall CE, Davison A, Doney SC, Fourquez M, Hurd CL, et al. Biological responses to environmental heterogeneity under future ocean conditions. Glob Change Biol. 2016;22:2633-50.

13. Ward CS, Yung C-M, Davis KM, Blinebry SK, Williams TC, Johnson ZI, et al. Annual community patterns are driven by seasonal switching between closely related marine bacteria. ISME J. 2017;11:1412-22.

14. Kan J, Crump BC, Wang K, Chen F. Bacterioplankton community in Chesapeake Bay: Predictable or random assemblages. Limnol Oceanogr. 2006;51:2157-69.

15. Kirchman DL, Cottrel MT, DiTullio GR. Shaping of bacterial community composition and diversity by phytoplankton and salinity in the Delaware Estuary, USA. Aquat Microb Ecol. 2017;78:93-106.

16. Stepanauskas R, Moran MA, Bergamaschi BA, Hollibaugh JT. Covariance of bacterioplankton composition and environmental variables in a temperate delta system. Aquat Microb Ecol. 2003;31:85-98.

17. Liu J, Fu B, Yang H, Zhao M, He B, Zhang X-H. Phylogenetic shifts of bacterioplankton community composition along the Pearl Estuary: the potential impact of hypoxia and nutrients. Front Microbiol. 2015;6:64. doi:10.3389/fmicb.2015.00064.

18. Fortunato CS, Herfort L, Zuber P, Baptista AM, Crump BC. Spatial variability overwhelms seasonal patterns in bacterioplankton communities across a river to ocean gradient. ISME J. 2012;6:554-63.

19. Hoch MP, Kirchman DL. Seasonal and inter-annual variability in bacterial production and biomass in a temperate estuary. Mar Ecol: Prog Ser. 1993;98:283-95.

20. Shish FK, Ducklow HW. Temperature regulation of heterotrophic bacterioplankton abundance, production, and specific growth rate in Chesapeake Bay. Limnol Oceanogr. 1994;39:1243-58.

21. Ladau J, Eloe-Fadrosh EA. Spatial, temporal, and phylogenetic scales of microbial ecology. Trends microbiol. 2019;27:662-9. 
22. Bouvier TC, del Giorgio PA. Compositional changes in free-living bacterial communities along a salinity gradient in two temperate estuaries. Limnol Oceanogr. 2002;47:453-70.

23. Maresca JA, Miller KJ, Keffer JL, Sabanayagam CR, Campbell BJ. Distribution and diversity of rhodopsin-producing microbes in the Chesapeake Bay. Appl Environ Microbiol. 2018;84:e00137-00118.

24. Fuhrman JA, Hewson I, Schwalbach MS, Steele JA, Brown MV, Naeem S. Annually reoccurring bacterial communities are predictable from ocean conditions. Proc Natl Acad Sci U S A. 2006;103:13104-9.

25. Bunse C, Pinhassi J. Marine bacterioplankton seasonal succession dynamics. Trends microbiol. 2017;25:494-505.

26. Fuhrman JA, Steele JA. Community structure of marine bacterioplankton: patterns, networks, and relationships to function. Aquat Microb Ecol. 2008;53:69-81.

27. Crump BC, Peterson BJ, Raymond PA, Amon RM, Rinehart A, McClelland JW, et al. Circumpolar synchrony in big river bacterioplankton. Proc Natl Acad Sci U S A. 2009;106:21208-12.

28. Chafee M, Fernàndez-Guerra A, Buttigieg PL, Gerdts G, Eren AM, Teeling H, et al. Recurrent patterns of microdiversity in a temperate coastal marine environment. ISME J. 2018;12:237-52.

29. Strom SL. Microbial ecology of ocean biogeochemistry: a community perspective. Science. 2008;320:1043-5.

30. Faust K, Raes J. Microbial interactions: from networks to models. Nat Rev Microbiol. 2012;10:538-50.

31. Coyte KZ, Schluter J, Foster KR. The ecology of the microbiome: networks, competition, and stability. Science. 2015;350:663-6.

32. Rooney N, McCann K, Gellner G, Moore JC. Structural asymmetry and the stability of diverse food webs. Nature. 2006;442:265-9.

33. Stouffer DB, Bascompte J. Compartmentalization increases food-web persistence. Proc Natl Acad Sci U S A. 2011;108:3648-52.

34. Kuiper JJ, Van Altena C, De Ruiter PC, Van Gerven LP, Janse JH, Mooij WM. Food-web stability signals critical transitions in temperate shallow lakes. Nat commun. 2015;6:1-7.

35. Morone F, Makse HA. Influence maximization in complex networks through optimal percolation. Nature. 2015;524:65-8.

36. Röttjers L, Faust K. From hairballs to hypotheses-biological insights from microbial networks. FEMS Microbiol Rev. 2018;42:761-80.

37. Zengler K, Zaramela LS. The social network of microorganisms - how auxotrophies shape complex communities. Nat Rev Microbiol. 2018;16:383-90.

38. Berry D, Widder S. Deciphering microbial interactions and detecting keystone species with co-occurrence networks. Front Microbiol. $2014 ; 5: 219$. doi:10.3389/fmicb.2014.00219.

39. de Vries FT, Griffiths RI, Bailey M, Craig H, Girlanda M, Gweon HS, et al. Soil bacterial networks are less stable under drought than fungal networks. Nat commun. 2018;9:3033. doi:10.1038/s41467-018-05516-7.

40. Barberán A, Bates ST, Casamayor EO, Fierer N. Using network analysis to explore co-occurrence patterns in soil microbial communities. ISME J. 2012;6:343-51.

41. Lima-Mendez G, Faust K, Henry N, Decelle J, Colin S, Carcillo F, et al. Determinants of community structure in the global plankton interactome. Science. 2015;348:1262073.

42. Steele JA, Countway PD, Xia L, Vigil PD, Beman JM, Kim DY, et al. Marine bacterial, archaeal and protistan association networks reveal ecological linkages. ISME J. 2011;5:1414-25.

43. Dai T, Zhang Y, Ning D, Su Z, Tang Y, Huang B, et al. Dynamics of sediment microbial functional capacity and community interaction networks in an urbanized coastal estuary. Front Microbiol. 2018;9:2731. doi:10.3389/fmicb.2018.02731.

44. Eiler A, Heinrich F, Bertilsson S. Coherent dynamics and association networks among lake bacterioplankton taxa. ISME J. 2012;6:330-42.

45. Mikhailov IS, Zakharova YR, Bukin YS, Galachyants YP, Petrova DP, Sakirko MV, et al. Co-occurrence networks among bacteria and microbial eukaryotes of Lake Baikal during a spring phytoplankton bloom. Microb Ecol. 2019;77:96-109.

46. Widder S, Besemer K, Singer GA, Ceola S, Bertuzzo E, Quince C, et al. Fluvial network organization imprints on microbial co-occurrence networks. Proc Natl Acad Sci U S A. 2014;111:12799-804.

47. Cardona C, Weisenhorn P, Henry C, Gilbert JA. Network-based metabolic analysis and microbial community modeling. Curr Opin Microbiol. 2016;31:12431.

48. Freilich S, Kreimer A, Meilijson I, Gophna U, Sharan R, Ruppin E. The large-scale organization of the bacterial network of ecological co-occurrence interactions. Nucleic Acids Res. 2010;38:3857-68.

49. Nixon SW, Ammerman JW, Atkinson LP, Berounsky VM, Billen G, Boicourt WC, et al. The fate of nitrogen and phosphorus at the land-sea margin of the North Atlantic Ocean. Biogeochemistry. 1996;35:141-80.

50. Berg C, Dupont CL, Asplund-Samuelsson J, Celepli NA, Eiler A, Allen AE, et al. Dissection of microbial community functions during a Cyanobacterial bloom in the Baltic Sea via metatranscriptomics. Front Mar Sci. 2018;5:55. doi:10.3389/fmars.2018.00055.

51. Kellogg CTE, McClelland JW, Dunton KH, Crump BC. Strong seasonality in arctic estuarine microbial food webs. Front Microbiol. 2019;10:2628. doi:10.3389/fmicb.2019.02628.

52. Watson SCL, Beaumont NJ, Widdicombe S, Paterson DM. Comparing the network structure and resilience of two benthic estuarine systems following the implementation of nutrient mitigation actions. Estuar Coast Shelf Sci. 2020;244:106059. doi:10.1016/j.ecss.2018.12.016.

53. Yao Z, Du S, Liang C, Zhao Y, Dini-Andreote F, Wang K, et al. Bacterial community assembly in a typical estuarine marsh with multiple environmental gradients. Appl Environ Microbiol. 2019;85:e02602-18. 
54. Wang H, Zhang C, Chen F, Kan J. Spatial and temporal variations of bacterioplankton in the Chesapeake Bay: A re-examination with high-throughput sequencing analysis. Limnol Oceanogr. 2020. doi:10.1002/Ino.11572.

55. Williams RJ, Howe A, Hofmockel KS. Demonstrating microbial co-occurrence pattern analyses within and between ecosystems. Front Microbiol. 2014;5:358. doi:10.3389/fmicb.2014.00358.

56. De'Ath G, De'Ath G. Multivariate regression trees: a new technique for modeling species-environment relationships. Ecology 83: 1105-1117. Ecology. 2001;83:1105-1117.

57. Lefcheck JS. piecewiseSEM. Piecewise structural equation modelling in r for ecology, evolution, and systematics. Methods Ecol Evol. 2016;7:573-9.

58. Yadav BK, Shrestha SR, Hassanizadeh SM. Biodegradation of toluene under seasonal and diurnal fluctuations of soil-water temperature. Water Air Soil Pollut. 2012;223:3579-88.

59. Kan J, Wang K, Chen F. Temporal variation and detection limit of an estuarine bacterioplankton community analyzed by denaturing gradient gel electrophoresis (DGGE). Aquat Microb Ecol. 2006;42:7-18.

60. Bolyen E, Rideout JR, Dillon MR, Bokulich NA, Abnet CC, Al-Ghalith GA, et al. Reproducible, interactive, scalable and extensible microbiome data science using QIIME 2. Nat Biotechnol. 2019;37:852-7.

61. Wang B and others 2018. Network enhancement as a general method to denoise weighted biological networks. Nat commun. 9: 3108 .

62. Gibson TE, Bashan A, Cao H-T, Weiss ST, Liu Y-Y. On the origins and control of community types in the human microbiome. PLoS comput Biol. 2016;12:e1004688.

63. Freeman LC. A set of measures of centrality based on betweenness. Sociometry. 1977;35-41.

64. Freeman LC. The gatekeeper, pair-dependency and structural centrality. Qual Quant. 1980;14:585-92.

65. Saavedra S, Stouffer DB, Uzzi B, Bascompte J. Strong contributors to network persistence are the most vulnerable to extinction. Nature. 2011;478:233-5.

66. Watts DJ, Strogatz SH. Collective dynamics of 'small-world'networks. nature. 1998;393:440.

67. Guidi L, Chaffron S, Bittner L, Eveillard D, Larhlimi A, Roux S, et al. Plankton networks driving carbon export in the oligotrophic ocean. Nature. 2016;532:465-70.

68. Mori JF, Ueberschaar N, Lu S, Cooper RE, Pohnert G, Küsel K. Sticking together: inter-species aggregation of bacteria isolated from iron snow is controlled by chemical signaling. ISME J. 2017;11:1075-86.

69. Zhou J, Deng Y, Luo F, He Z, Tu Q, Zhi X. Functional molecular ecological networks. MBio. 2010;1:e00169-00110.

70. Pocock MJ, Evans DM, Memmott J. The robustness and restoration of a network of ecological networks. Science. 2012;335:973-7.

71. Newman ME, Girvan M. Finding and evaluating community structure in networks. Phys Rev E. 2004;69:026113.

72. De"ath. Glenn. Multivariate regression trees: a new technique for modeling species-environment relationships. Ecology. 2002;83:1105-17.

73. Grace JB. Structural equation modeling and natural systems. Cambridge University Press; 2006.

74. Schermelleh-Engel K, Moosbrugger H, Müller H. Evaluating the fit of structural equation models: tests of significance and descriptive goodness-of-fit measures. Mpr Online. 2003;8:23-74.

75. Shipley B. The AIC model selection method applied to path analytic models compared using ad-separation test. Ecology. 2013;94:560-4.

76. Newman MEJ. Modularity and community structure in networks. Proc Natl Acad Sci U S A. 2006;103:8577-82.

77. Watts DJ, Strogatz SH. Collective dynamics of 'small-world' networks. Nature. 1998;393:440-2.

78. Falkowski P, Jelen BI. Microbial genomes that drive earth's biogeochemical cycles. Springer. 2013. https://doi.org/10.1007/978-1-4614-6418-1_800-3.

79. Russell JA, Dubilier N, Rudgers JA. Nature's microbiome: introduction. Mol Ecol. 2014;23:1225-37.

80. Xue Y, Chen H, Yang JR, Liu M, Huang B, Yang J. Distinct patterns and processes of abundant and rare eukaryotic plankton communities following a reservoir cyanobacterial bloom. ISME J. 2018;12:2263-77.

81. Debroas D, Hugoni M, Domaizon I. Evidence for an active rare biosphere within freshwater protists community. Mol Ecol. 2015;24:1236-47.

82. Lynch MD, Neufeld JD. Ecology and exploration of the rare biosphere. Nat Rev Microbiol. 2015;13:217-29.

83. Jousset A, Bienhold C, Chatzinotas A, Gallien L, Gobet A, Kurm V, et al. Where less may be more: how the rare biosphere pulls ecosystems strings. ISME J. 2017;11:853-62.

84. Julia G, Wick LY, Antonis C, Hauke H. Alkane-degrading bacteria at the soil-litter interface: comparing isolates with T-RFLP-based community profiles. FEMS Microbiol Ecol. 45-58.

85. Benda L, Poff NL, Miller D, Dunne T, Reeves G, Pess G, et al. The network dynamics hypothesis: how channel networks structure riverine habitats. Bioscience. 2004;54:413-27.

86. Gibson TE, Bashan A, Cao H-T, Weiss ST, Liu Y-Y. On the origins and control of community types in the human microbiome. PLoS Comput Biol. 2016;12:e1004688.

87. Shade A, Jones SE, Caporaso JG, Handelsman J, Knight R, Fierer N, et al. Conditionally rare taxa disproportionately contribute to temporal changes in microbial diversity. MBio. 2014;5:e01371-01314.

88. Shade A, Gilbert JA. Temporal patterns of rarity provide a more complete view of microbial diversity. Trends Microbiol. 2015;23:335-40.

89. Kirchman DL, Dittel Al, Malmstrom RR, Cottrell MT. Biogeography of major bacterial groups in the Delaware Estuary. Limnol Oceanogr. 2005;50:1697706. 
90. Herlemann DPR, Labrenz M, Jürgens K, Bertilsson S, Waniek JJ, Andersson AF. Transitions in bacterial communities along the 2000 km salinity gradient of the Baltic Sea. ISME J. 2011;5:1571-9.

91. Chow C-ET, Sachdeva R, Cram JA, Steele JA, Needham DM, Patel A, et al. Temporal variability and coherence of euphotic zone bacterial communities over a decade in the Southern California Bight. ISME J. 2013;7:2259-73.

92. de Jonge VN, Schückel U, Baird D. Effects of spatial scale, species aggregation and balancing on carbon flows and ecological network analysis indicators of food webs. Mar Ecol: Prog Ser. 2019;613:15-47.

93. Kara EL, Hanson PC, Hu YH, Winslow L, McMahon KD. A decade of seasonal dynamics and co-occurrences within freshwater bacterioplankton communities from eutrophic Lake Mendota, WI, USA. ISME J. 2013;7:680-4.

94. Czárán TL, Hoekstra RF, Pagie L. Chemical warfare between microbes promotes biodiversity. Proc Natl Acad Sci U S A. 2002;99:786-90.

95. Montoya JM, Pimm SL, Solé RV. Ecological networks and their fragility. Nature. 2006;442:259-64.

96. Fuhrman JA. Microbial community structure and its functional implications. Nature. 2009;459:193-9.

97. Saleem M, Fetzer I, Dormann CF, Harms H, Chatzinotas A. Predator richness increases the effect of prey diversity on prey yield. Nat commun. 2012;3:1305.

98. Tilman D, Lehman CL, Thomson KT. Plant diversity and ecosystem productivity: theoretical considerations. Proc Natl Acad Sci U S A. 1997;94:1857-61.

99. Loreau M. Biodiversity and ecosystem functioning: a mechanistic model. Proc Natl Acad Sci U S A. 1998;95:5632-6.

100. Cardinale BJ, Palmer MA, Collins SL. Species diversity enhances ecosystem functioning through interspecific facilitation. Nature. 2002;415:426.

101. Crump BC, Hopkinson CS, Sogin ML, Hobbie JE. Microbial biogeography along an estuarine salinity gradient: combined influences of bacterial growth and residence time. Appl Environ Microbiol. 2004;70:1494-505.

102. Chafee $M$, Fernàndez-Guerra A, Buttigieg PL, Gerdts $G$, Eren $A M$, Teeling $H$, et al. Recurrent patterns of microdiversity in a temperate coastal marine environment. ISME J. 2017;12:237.

103. Gilbert JA, Steele JA, Caporaso JG, Steinbrück L, Reeder J, Temperton B, et al. Defining seasonal marine microbial community dynamics. ISME J. 2012;6:298-308.

104. Zhu J, Hong Y, Zada S, Hu Z, Wang H. Spatial variability and co-acclimation of phytoplankton and bacterioplankton communities in the Pearl River Estuary, China. Front Microbiol. 2018;9:2503. doi:10.3389/fmicb.2018.02503.

105. Donohue I and others. Navigating the complexity of ecological stability. Ecol Lett. 2016;19:1172-1185.

106. Domínguez-García V, Dakos V, Kéfi S. Unveiling dimensions of stability in complex ecological networks. Proc Natl Acad Sci U S A. 2019;116:25714-20.

107. Pimm SL. The complexity and stability of ecosystems. Nature. 1984;307:321-6.

108. Holling CS. Resilience and Stability of Ecological Systems. Annu Rev Ecol Syst. 1973;4:1-23.

109. King AJ, Farrer EC, Suding KN, Schmidt SK. Co-occurrence patterns of plants and soil bacteria in the high-alpine subnival zone track environmental harshness. Front Microbiol. 2012;3:347.

110. Pinhassi J, Hagström Å. Seasonal succession in marine bacterioplankton. Aquat Microb Ecol. 2000;21:245-56.

111. Xiao Y, Angulo MT, Friedman J, Waldor MK, Weiss ST, Liu Y-Y. Mapping the ecological networks of microbial communities. Nat commun. $2017 ; 8: 2042$.

112. Cerco CF, Noel MR. Twenty-one-year simulation of Chesapeake Bay water quality using the CE-QUAL-ICM eutrophication model. J AM Water Resour AS. 2013;49:1119-33.

113. Harding LW and others 2016. Long-Term Trends of Nutrients and Phytoplankton in Chesapeake Bay. Estuar Coast. 39: 664-681.

114. Williams MR, Filoso S, Longstaff BJ, Dennison WC. Long-Term Trends of Water Quality and Biotic Metrics in Chesapeake Bay: 1986 to 2008. Estuar Coast. 2010;33:1279-99.

115. Suttle CA. Marine viruses-major players in the global ecosystem. Nat Rev Microbiol. 2007;5:801-12.

116. Chow C-ET, Kim DY, Sachdeva R, Caron DA, Fuhrman JA. Top-down controls on bacterial community structure: microbial network analysis of bacteria, T4like viruses and protists. ISME J. 2014;8:816-29.

117. Knowles B, Silveira CB, Bailey BA, Barott K, Cantu VA, Cobián-Güemes AG, et al. Lytic to temperate switching of viral communities. Nature. 2016;531:46670 .

\section{Tables}

Table 1. Topological properties of microbial co-occurrence networks in the Chesapeake Bay 


\begin{tabular}{|c|c|c|c|c|c|c|c|c|c|c|c|c|}
\hline Groups & Nodes & Edges & $\begin{array}{l}\text { Fragmentation } \\
\text { (f) }\end{array}$ & $\begin{array}{l}\text { Average } \\
\text { degree }\end{array}$ & $\begin{array}{l}\text { Network } \\
\text { diameter }\end{array}$ & $\begin{array}{l}\text { Graph } \\
\text { density }\end{array}$ & Modularity & Components & $\begin{array}{l}\text { Average } \\
\text { Clustering } \\
\text { Coefficient }\end{array}$ & $\begin{array}{l}\text { Average } \\
\text { path } \\
\text { length }\end{array}$ & $\begin{array}{l}\text { Number } \\
\text { of } \\
\text { Clusters }\end{array}$ & $\begin{array}{l}\text { Numl } \\
\text { nega: } \\
\text { corre }\end{array}$ \\
\hline All & 387 & 4130 & 0.18 & 21.3 & 8 & 0.055 & 0.513 & 3 & 0.509 & 3.118 & 7 & 286 \\
\hline All ${ }^{\mathrm{a}}$ & 377 & 3917 & 0.23 & 20.8 & 8 & 0.055 & 0.506 & 4 & 0.506 & 3.137 & 9 & 265 \\
\hline All ${ }^{b}$ & 377 & 3525 & 0.19 & 18.7 & 8 & 0.050 & 0.54 & 3 & 0.497 & 3.163 & 8 & 272 \\
\hline All ${ }^{c}$ & 377 & 3855 & 0.27 & 20.5 & 8 & 0.054 & 0.498 & 5 & 0.509 & 3.222 & 9 & 241 \\
\hline Winter & 331 & 3430 & 0.12 & 20.7 & 8 & 0.063 & 0.554 & 2 & 0.392 & 2.822 & 9 & 526 \\
\hline Spring & 340 & 3296 & 0 & 19.4 & 8 & 0.057 & 0.576 & 1 & 0.413 & 2.866 & 6 & 513 \\
\hline Summer & 338 & 3983 & 0 & 23.6 & 6 & 0.070 & 0.576 & 1 & 0.427 & 2.638 & 6 & 720 \\
\hline Autumn & 337 & 3790 & 0 & 22.5 & 6 & 0.067 & 0.591 & 1 & 0.446 & 2.700 & 6 & 707 \\
\hline $\begin{array}{l}\text { Upper } \\
\text { Bay }\end{array}$ & 367 & 4526 & 0 & 24.7 & 7 & 0.067 & 0.538 & 1 & 0.474 & 2.859 & 7 & 344 \\
\hline $\begin{array}{l}\text { Lower } \\
\text { Bay }\end{array}$ & 376 & 5012 & 0 & 26.7 & 8 & 0.071 & 0.534 & 1 & 0.479 & 2.799 & 7 & 559 \\
\hline
\end{tabular}

a after removal of top 10 nodes with the highest abundance

${ }^{b}$ after removal of top 10 nodes with the most degree

${ }^{c}$ after removal of top 10 nodes with the most betweenness centrality

\section{Figures}
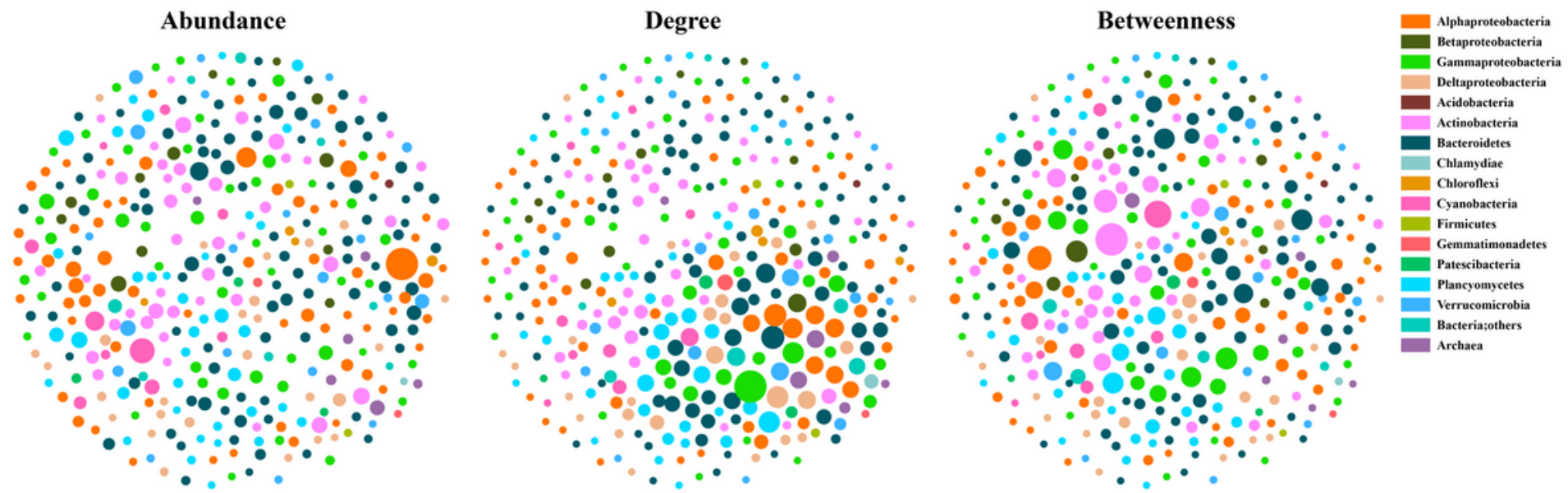

Figure 1

Co-occurrence networks of planktonic microbiomes in the Chesapeake Bay. Color coded nodes represent major bacterial ASVs. The relative abundance, degree or betweenness centrality of each ASV are shown by node sizes. Red lines and black lines represent significant negative or positive correlations. 
Winter

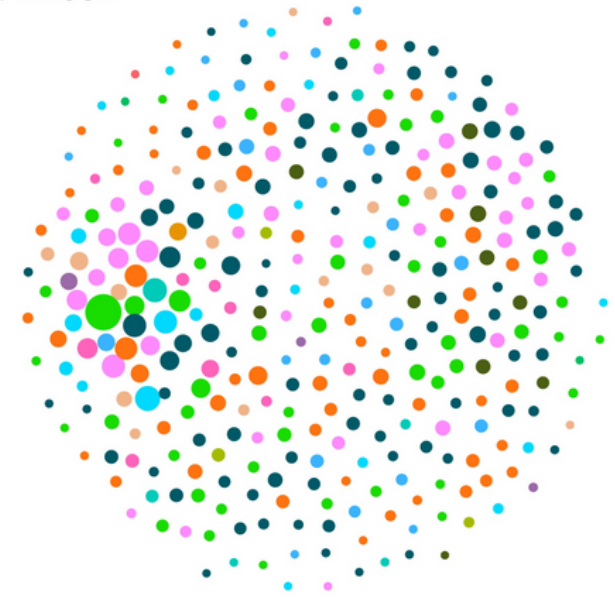

\section{Summer}

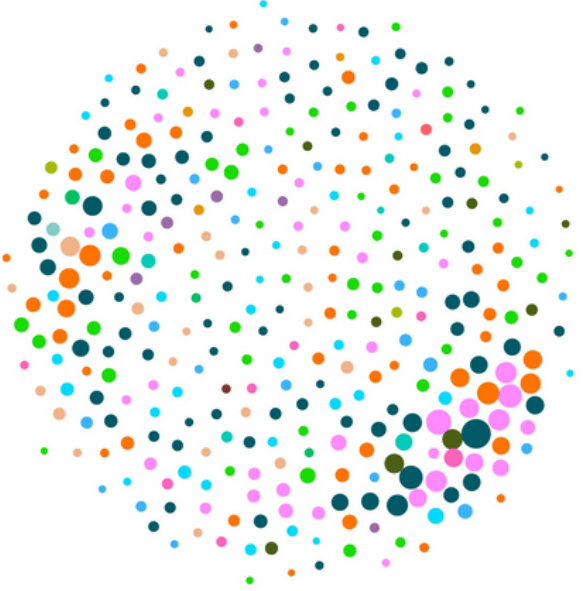

\section{Spring}

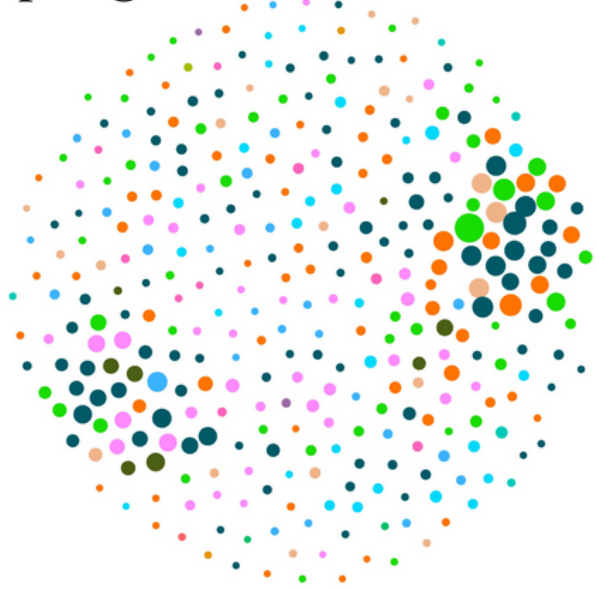

Autumn

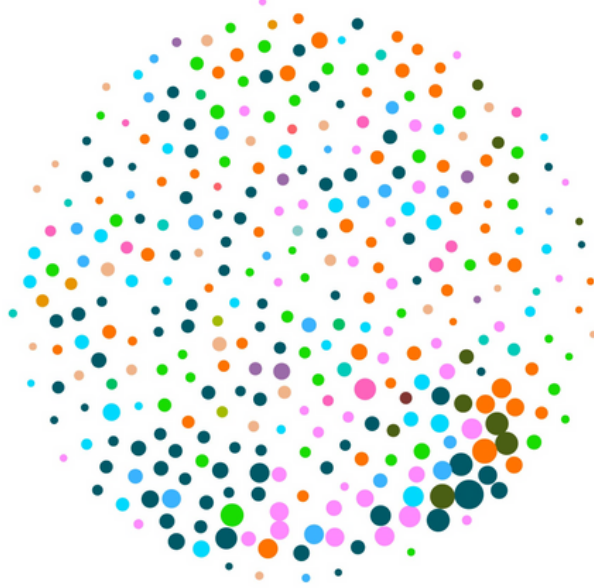

Alphaproteobacteria

Betaproteobacteria

Gammaproteobacteria

Deltaproteobacteria

Acidobacteria

Actinobacteria

Bacteroidetes

Chlamydiae

Chloroflexi

Cyanobacteria

Firmicutes

Gemmatimonadetes

Patescibacteria

Plancyomycetes

Verrucomicrobia

Bacteria;others

Archaea

Figure 2

The architecture of microbial networks in winter, spring, summer, and autumn. Color-coded nodes represent the major bacterial ASVs within each network. Node sizes indicate number of connections (degree) for each node (ASV). Negative and positive correlations are shown in red or black lines.

\section{Upper Bay}

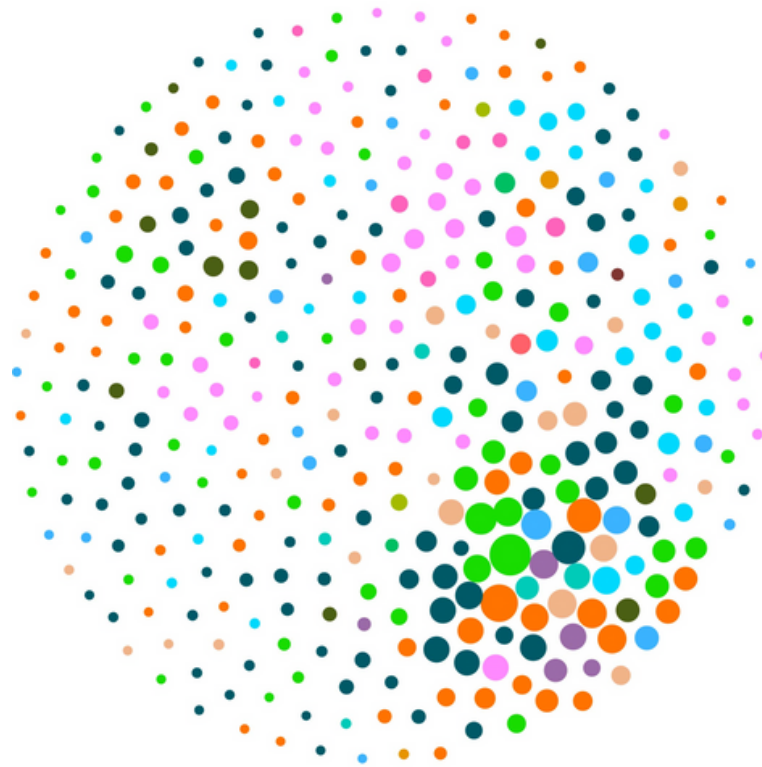

\section{Lower Bay}

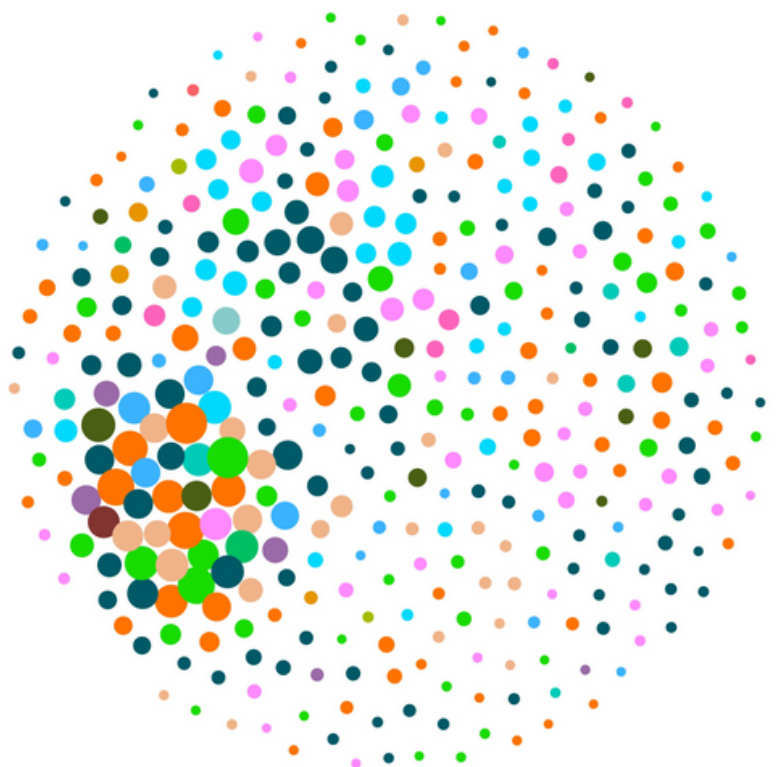

Alphaproteobacteria Betaproteobacteria

Gammaproteobacteria Deltaproteobacteria Acidobacteria Actinobacteria Bacteroidetes Chlamydiae

Chloroflexi

Cyanobacteria Firmicutes Gemmatimonadetes Patescibacteria Plancyomycetes Verrucomicrobia Bacteria;others Archaea

Figure 3 
Microbial co-occurrence networks in upper Bay and lower Bay. Color-coded nodes represent major bacterial ASVs. Node sizes indicate number of connections (degree) for each node (ASV). Negative and positive correlations are shown in red or black lines.

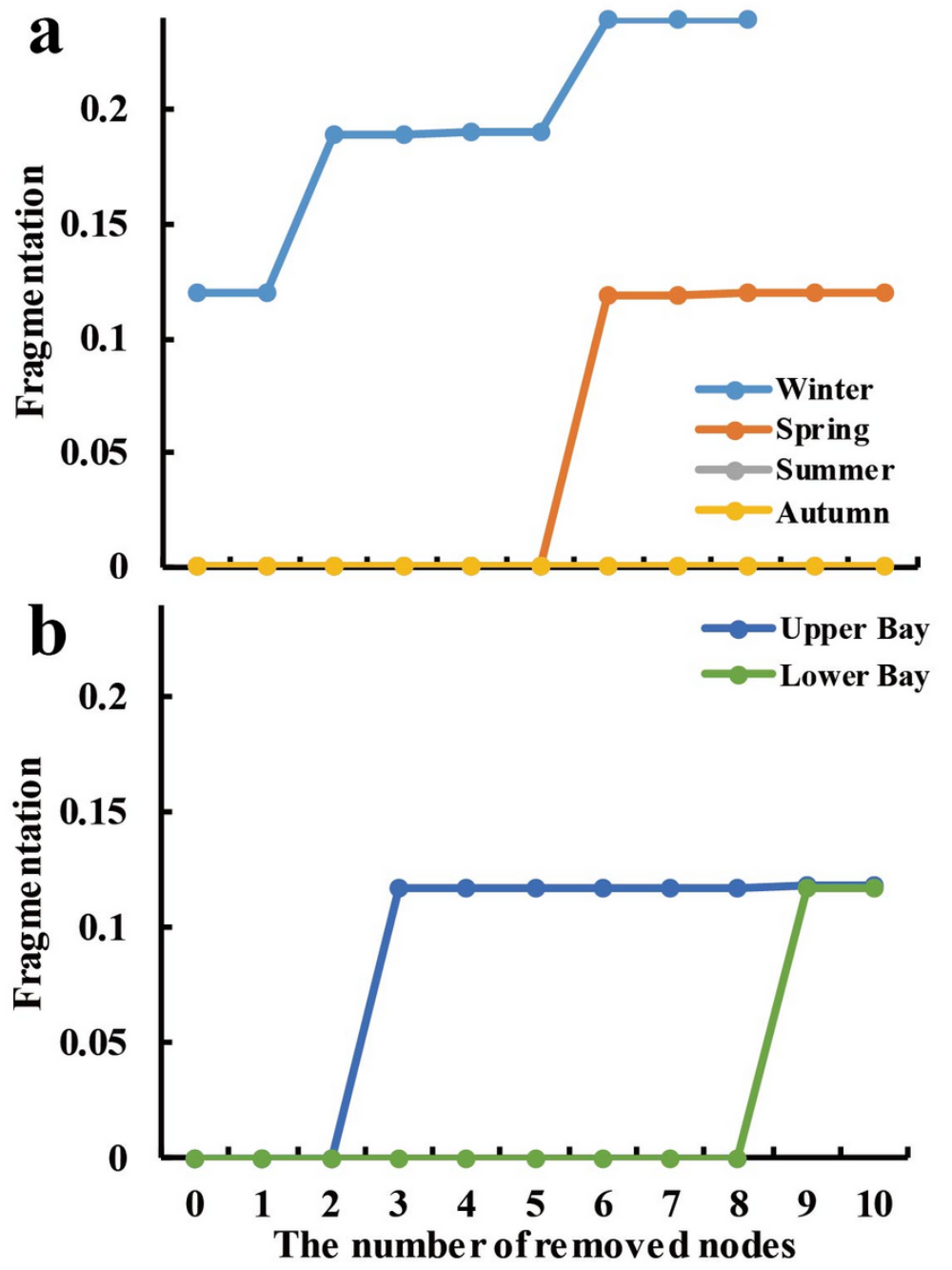

Figure 4

The fragmentations of co-occurrence networks with consecutive removal of 10 nodes with the highest betweenness centrality for four seasons (a) and upper/lower Bay (b) bacterial networks. 

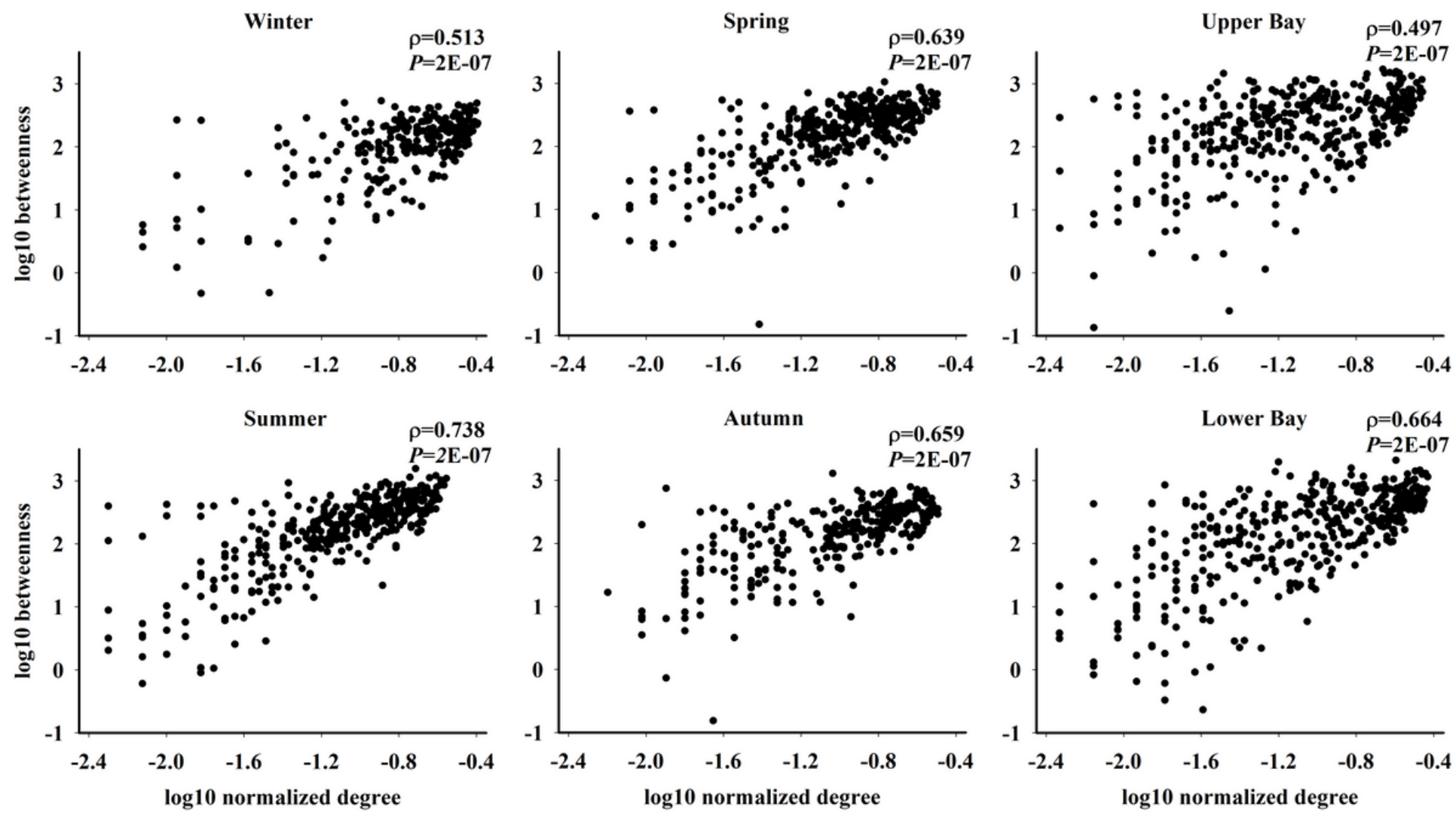

Figure 5

Correlations between normalized degree and betweenness in seasonal and spatial networks. 


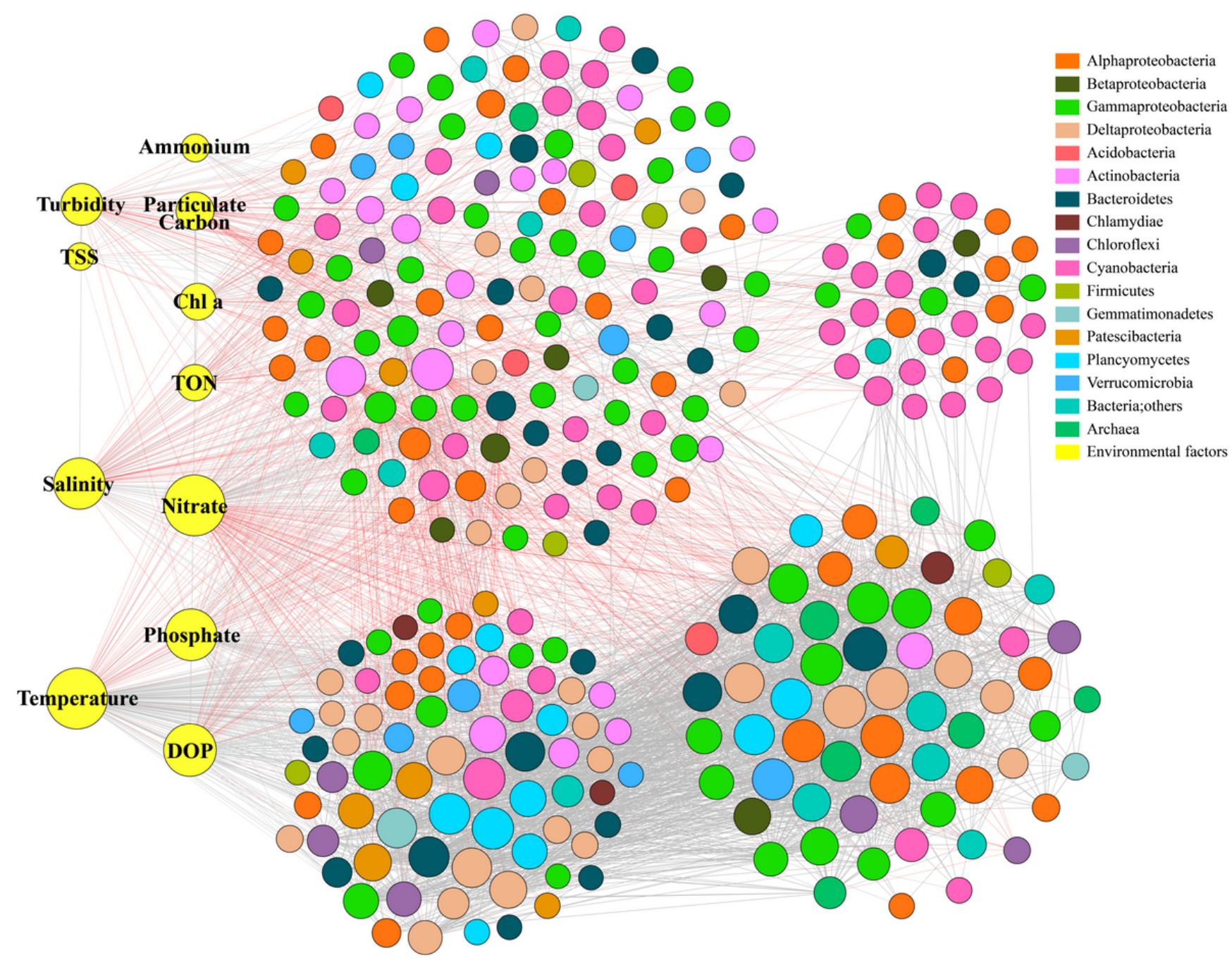

Figure 6

The association network of microbiomes and environmental factors. Color-coded nodes represent major bacterial ASVs. Red lines and black lines indicate significant negative or positive correlations $(P<0.05$, Q-value $<0.05)$. Significant and strong correlations $(P<0.05, Q-v a l u e<0.05$, and $|r| \geq 0.6)$ between microbial taxa are shown. TSS, total suspended solids; TON, total organic nitrogen; DOP, dissolved organic phosphorus. 


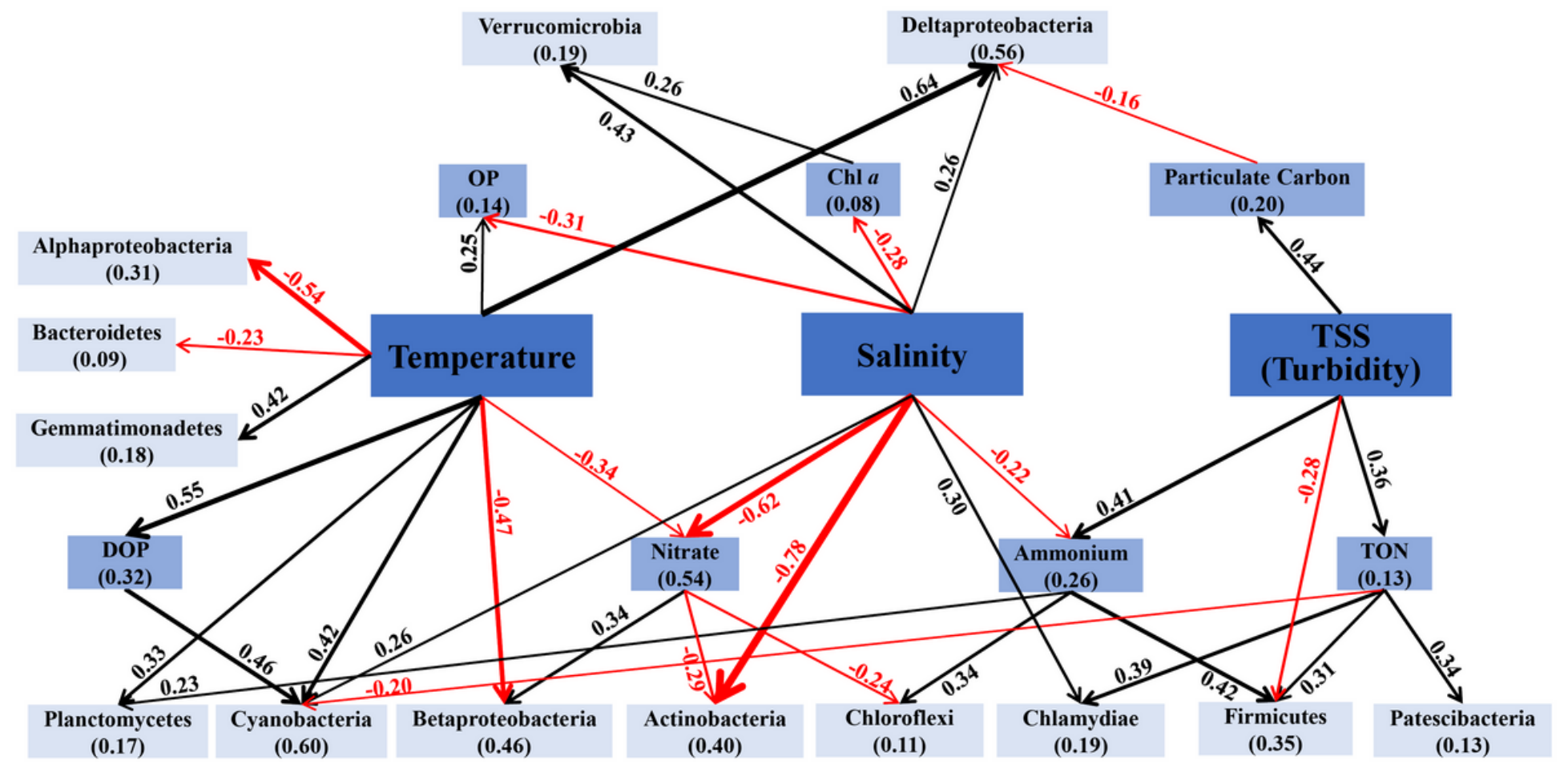

Figure 7

Structural equation model to demonstrate the connections between environmental factors and planktonic microbiome distributions. Red lines, black lines and the associated numbers indicate significant negative or positive correlations and the standard estimates. The thickness of arrows and the number associated with each line represent the strength of correlations. Numbers in parenthesis shows the explanation degree for each factor.

\section{Supplementary Files}

This is a list of supplementary files associated with this preprint. Click to download.

- Figures1.tiff

- Figures2.jpeg

- Figures3.png

- FigureS4.png

- Figures5.tiff

- Supplementaryinformation.docx

- Tables1.xlsx

- Tables2.xlsx

- Tables3.xlsx

- Tables4.xlsx

- Tables5.xisx

- Tables6.xIsx 